\title{
Pectoralis muscle area and mortality in smokers without airflow obstruction
}

\author{
Alejandro A. Diaz ${ }^{1 *}$, Carlos H. Martinez ${ }^{2}$, Rola Harmouche³, Thomas P. Young ${ }^{1}$, Merry-Lynn McDonald ${ }^{4}$, \\ James C. Ross ${ }^{3}$, Mei Lan Han², Russell Bowler ${ }^{5}$, Barry Make ${ }^{5}$, Elizabeth A. Regann ${ }^{5}$, Edwin K. Silverman ${ }^{1,6}$, \\ James Crapo ${ }^{5}$, Aladin M. Boriek7, Gregory L. Kinney ${ }^{8}$, John E. Hokanson ${ }^{8}$, Raul San Jose Estepar ${ }^{3}$ \\ and George R. Washko'
}

\begin{abstract}
Background: Low muscle mass is associated with increased mortality in the general population but its prognostic value in at-risk smokers, those without expiratory airflow obstruction, is unknown. We aimed to test the hypothesis that reduced muscle mass is associated with increased mortality in at-risk smokers.

Methods: Measures of both pectoralis and paravertebral erector spinae muscle cross-sectional area (PMA and PVMA, respectively) as well as emphysema on chest computed tomography (CT) scans were performed in 3705 current and former at-risk smokers ( $\geq 10$ pack-years) aged $45-80$ years enrolled into the COPDGene Study between 2008 and 2013. Vital status was ascertained through death certificate. The association between low muscle mass and mortality was assessed using Cox regression analysis.

Results: During a median of 6.5 years of follow-up, 212 (5.7\%) at-risk smokers died. At-risk smokers in the lowest (vs. highest) sex-specific quartile of PMA but not PVMA had 84\% higher risk of death in adjusted models for demographics, smoking, dyspnea, comorbidities, exercise capacity, lung function, emphysema on $C T$, and coronary artery calcium content (hazard ratio [HR] 1.85 95\% Confidence interval [1.14-3.00] $P=0.01$ ). Results were consistent when the PMA index (PMA/height ${ }^{2}$ ) was used instead of quartiles. The association between PMA and death was modified by smoking status $(P=0.04)$. Current smokers had a significantly increased risk of death (lowest vs. highest PMA quartile, HR 2.25 [1.25-4.03] $P=0.007$ ) while former smokers did not.
\end{abstract}

Conclusions: Low muscle mass as measured on chest $C T$ scans is associated with increased mortality in current smokers without airflow obstruction.

Trial registration: NCT00608764

Keywords: Pectoralis muscle mass, CT, Smoking, Paravertebral muscle mass

\section{Background}

There are an estimated 40 million current smokers in the United States [1] and such noxious exposure is linked to cancer, cardiovascular disease, and respiratory conditions such as chronic obstructive pulmonary disease (COPD). Recent investigation suggests that even smokers without expiratory airflow obstruction experience

\footnotetext{
* Correspondence: ADiaz6@Partners.org

Alejandro A. Diaz and Carlos H. Martinez contributed equally to this

work.Raul San Jose Estepar and George R. Washko are co-senior authors.

${ }^{1}$ Division of Pulmonary and Critical Care Medicine, Department of Medicine,

Brigham and Women's Hospital, Harvard Medical School, 75 Francis Street,

Boston, MA 02115, USA

Full list of author information is available at the end of the article
}

symptomatic impairment and decrements in health status and exercise capacity [2, 3]. Further, smokers without airflow obstruction (hereafter referred to as at-risk smokers) present changes in skeletal muscle structure and have low muscle mass similar to those with COPD [4-8]. Low muscle mass is frequent and associated with increased risk for death in the general population [9-12] and those with COPD [13-17] and cancer [18]. It is unclear, however, if low skeletal muscle mass in at-risk smokers has prognostic value. Such knowledge would provide new insight into the multiple comorbidities present in those susceptible to injury from chronic tobacco smoke exposure, which in turn could result in improved clinical care. 
A variety of techniques such as bioimpedance and dual energy X-ray absorbance have been used to assess fatfree mass, a surrogate for muscle mass [14, 19-21]. These assessments are, however, holistic and cannot discriminate muscle-specific changes or their unique clinical significance. Such efforts have been undertaken using computed tomographic (CT) imaging. A myriad of studies has demonstrated that the CT cross-sectional area of mid-thigh, pectoralis, and paravertebral erector spinae muscles are associated with fat-free mass, handgrip strength, exercise capacity, health status, and COPD severity [22-25]. These CT measures were also predictive of mortality in subjects with established COPD [23, 24, 26]. Additionally, CT allows measuring fat depots including subcutaneous adipose tissue and thus provides additional prognostic understanding of the body composition [27].

Based on prior studies, $[15,23,24]$ we hypothesized that CT measures of body composition including distinct skeletal muscle groups would differentially predict death in at-risk smokers. To test this hypothesis, we examined the CT and clinical data obtained in the COPDGene Study [28].

\section{Methods}

The institutional review board of each of the 21 participating centers approved the study and all participants gave written informed consent. The Partners HealthCare Research Committee approved the current analysis (2007P-000554). Methodological details are provided in this section as well as in the online supplement. Briefly, COPDGene enrolled 10,192 Non-Hispanic white and African-American current and former smokers (10 or more pack-years) who were $45-80$ years old between 2008 and 2013 [28]. Smokers with active lung diseases other than COPD, emphysema, or asthma were excluded. In this analysis, we used smokers who did not meet criteria for COPD as defined by spirometry (see below) and had complete data on mortality, muscle measurements and other relevant covariates (Fig. 1). Data on PMA and mortality in smokers with COPD was presented as part of a separate report [26].

\section{COPDGene imaging protocol}

Chest CT images without the administration of intravenous iodinated contrast were obtained with subjects in the supine position at both full inflation (approximating total lung capacity) and relaxed exhalation (approximating functional residual capacity). Acquisition parameters included: $120 \mathrm{kVp}, 200 \mathrm{mAs}$, and 0.5 rotation time. Images were reconstructed using the following filters, slice thicknesses and spacing: standard, B31f, and B kernel; 0. $625,0.75$, and $0.90 \mathrm{~mm}$ slice thickness; $0.625,0.5$, and 0 . $45 \mathrm{~mm}$ slice interval for General Electric Medical

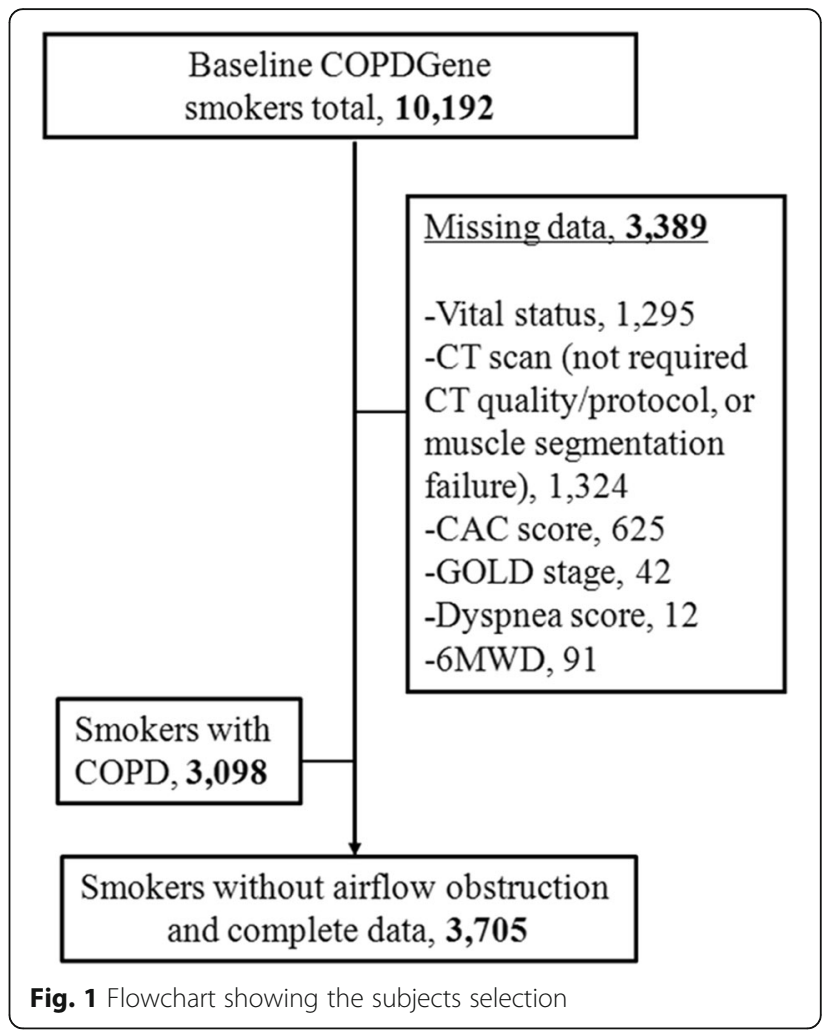

System, Siemens, and Philips scanners, respectively [29]. Data collected from the inspiratory CT scans included densitometric measures of the parenchyma, body composition (pectoralis muscle area [PMA], paravertebral erector spinae muscle area [PVMA], and subcutaneous adipose tissue $[\mathrm{SAT}]$ ), and coronary artery calcium (CAC) content. Emphysema-like tissue was defined as percentage of low attenuation areas below -950 (\%LAA-950) Hounsfield units (HU) evident on the inspiratory CT scans and was assessed using the Chest Imaging Platform (www.chestimagingplatform.org) [30].

\section{CT muscle measurements}

The PMA, PVMA, and SAT measurements were performed on inspiratory CT scans by trained analysts who were blinded to subjects' data [22, 27]. For the PMA, the analyst visually identified the superior aspect of the aortic arch and then the first axial slice above the arch. This location was chosen because it was easy to identify and could be replicated across a large cohort of participants. The left and right pectoralis major and minor muscles were then identified on the anterior chest and their edges manually segmented using a pre-defined attenuation range of -50 and $90 \mathrm{HU}$. The intra- and interanalyst concordance correlation coefficients (CCC) for PMA were 1.00 to 0.98 , respectively [27]. The PVMA was measured on a single-axial slice at the level of spinous process of the first lumbar vertebrae using the same 
HU thresholds utilized for PMA. A subset of 19 subjects was used to measure the intra- and inter-analyst agreement of PVMA. The SAT was defined as the region of interest between the pectoralis major muscles and skin surface on those same axial slices used to measure PMA and their edges were manually determined using a range of -200 and $0 \mathrm{HU}$. The intra- and inter-analyst CCC for SAT were 1.00 and 0.99 , respectively [27]. We used this limited subcutaneous fat region because the entire circumference of the chest was not available in many CT scans. As the focus of this investigation was the effect of low muscle mass on mortality, PMA, PVMA, and SAT were divided in 4 groups using the sex-specific quartile cut-off points with the quartile with the highest cross sectional area (4th) acting as the referent subgroup for the main analyses. We used sex-specific quartiles because of marked sex-based differences in PMA [27]. In a secondary analysis, the PMA was also expressed as an index (muscle cross-sectional area/height ${ }^{2}$ ) to account for between-subject differences in body size where lower index values indicate lower muscle mass.

\section{Coronary artery calcium assessment}

Previous investigation of the COPDGene data demonstrated a strong correlation between CAC measured on non-cardiac- and electrocardiographically-gated (cardiac) CT scans $(r=0.96)$ [31]. Coronary calcium was identified in 3 contiguous voxels by using a cutoff point of $130 \mathrm{HU}$ resulting in a minimum calcified lesion area of $1.02 \mathrm{~mm}^{2}$ and a lesion score was calculated as the product of lesion area and CT attenuation. The attenuation factor is derived from the maximal $\mathrm{HU}$ within the area as described by Agatston, ranging from 1 to 4 . A total CAC score was obtained by aggregating individual lesion scores from each of 4 anatomic sites (left main, left anterior descending, circumflex, and right coronary arteries). CAC has been used to detect subclinical atherosclerosis [32, 33] and details of coronary artery calcium assessment have been described elsewhere [31, 34, 35]. A subject's CAC score of 0 Agatston Unit indicates absence of calcium. Because CAC scores are not normally distributed, it was log transformed.

\section{Clinical and lung function assessments}

Clinical data including eight comorbidities and medication use were collected with standardized questionnaires, which are available at www.copdgene.org. Comorbidities including congestive heart failure, stroke, gastroesophageal reflux, cancer, diabetes mellitus, hypertension, coronary artery disease, and asthma were coded based on combining self-reported physician diagnosed conditions and medication use for these conditions. If the participant responded yes to the following question: "Have you ever been told by a physician that you have [condition name]?" was considered to have congestive heart failure, stroke, gastroesophageal reflux, and cancer. Additionally, diabetes and hypertension were considered present if the participant had responded yes to the above question and he/she was receiving treatment for those conditions. Positive responses about heart attack, angina, and coronary artery disease as well as self-report history of angioplasty, cardiac stent, or coronary artery bypass surgery were combined into one condition defined as coronary artery disease. Participants were considered to have had asthma if they responded yes to all the following questions: "Have you ever had asthma?", "Was it diagnosed by a doctor or other health professional?" "Do you still have it?" [36] Comorbidities were grouped as $0,1-2$, and 3 or more [37]. Body mass index (BMI) measures were also collected at baseline [38]. Dyspnea was evaluated using the modified Medical Research Council (MMRC) Dyspnea score. Exercise capacity was measured using the six-minute walk distance (6MWD) test [39]. Spirometric measures of lung function were conducted following the American Thoracic Society recommendations and the post-bronchodilator forced expiratory volume in one second $\left(\mathrm{FEV}_{1}\right)$ and forced vital capacity $(\mathrm{FVC})$ were expressed as percent of predicted values [40, 41]. Ever smokers whose $\mathrm{FEV}_{1} / \mathrm{FVC}$ ratio was $\geq 0.7$ were defined as "at-risk" smokers [42].

\section{Mortality ascertainment}

Vital status ascertainment was performed through the Social Security Death Index (SSDI) and the COPDGene longitudinal follow-up (LFU) program. Vital status for those who were searched via SSDI were back censored by 3 months to account for expected lag time between a death and subsequent annotation in the SSDI dataset. Vital status for those in whom consistent follow-up was supplied via the LFU program was censored on April 15th, 2015. For LFU participants who died prior to this date, the death was used if an LFU contact was performed in the previous six months. The median follow-up was 6 . 5 years. We used all-cause mortality as the outcome of interest.

\section{Statistical analysis}

Data are presented as mean $\pm \mathrm{SD}$, numbers, and proportion (\%). We performed Kaplan-Meier cumulative survival probability plots by sex-based quartiles of PMA, PVMA, and SAT. The log rank test was used to compare survival across groups. Multivariable Cox proportional hazards models were used to assess the association between measures of body composition and mortality. The body composition measurements that were statistically significant in univariate Kaplan-Meier analysis were used for multivariable modeling. Covariates included age, sex, race, height (to account for differences in body size), 
body mass index ([BMI] categories, <20, 20-24.9, 25$25.9, \geq 30$ ), current smoking status, pack-years of smoking (per 10), dyspnea score (categories, $0-1, \geq 2$ ), the number of comorbidities (categories, 0, 1-2, $\geq 3$ ), 6MWD (per $30 \mathrm{~m}$ ), $\mathrm{FEV}_{1}$, log \%LAA-950 on CT, log CAC score, and scanner brand/make. Interactions between PMA and age, sex, race, and smoking status (current and former) were also tested. The final models were checked to meet hazard proportionality assumptions. The intra- and inter-analyst agreement assessment for PVMA was performed using the CCC. Analyses were performed with SAS 9.4 (SAS Institute, Cary NC) using an alpha-error value of 0.05 .

\section{Results}

The intra- and inter-analyst CCC for PVMA was 0.964 and 0.947 , respectively. Complete clinical, CT, and vital status data were available in 3705 at-risk ever smokers (Fig. 1). PMA and PVMA were significantly correlated $\left(R^{2}=0.44 \quad P<0.0001\right)$ each other (Additional file 1: Figure S1). The baseline characteristics of the cohort are provided by PMA quartile in Table 1 and by PVMA quartile (Additional file 1: Table S1). Those in the lowest (vs. highest) quartiles of PMA were more likely to be older, female, non-Hispanic white and former smokers.
These subjects also were shorter, and had lower BMI and CAC score as well as higher \%LAA-950 on CT scan. The $\mathrm{FEV}_{1} \%$ predicted, $\mathrm{FVC} \%$ predicted, and $6 \mathrm{MWD}$ were similar between these two groups. When examined by PVMA quartile (Additional file 1: Table S1) the trends were similar to those of PMA quartiles but for \%LAA-950. \%LAA-950 was not significantly different between the lowest and highest PVMA quartiles. In the overall cohort, there were substantial differences in PMA and PVMA between men and women $(54.7 \pm 16.6$ vs. $\left.34.0 \pm 9.8 \mathrm{~cm}^{2}, P<.0001\right)$, which is the basis for conducting the main analyses using sex-specific quartiles of these CT metrics.

There were 212 deaths among the 3705 subjects during a median follow-up of 6.5 years. The number of the deaths were higher among at-risk smokers falling in the 2 lowest quartiles of PMA $(N=131,61.7 \%)$ and current smokers $(N=148,[69.8 \%])$. The Kaplan-Meier plots demonstrate that the probability of survival decreased with decreasing PMA (log-rank test $P=0.006$ ) (Fig. 2). There was no relationship between PVMA quartiles and mortality (log-rank test $P=0.59$ ) as well as between SAT quartiles and mortality (log-rank test $P=0.50$ ). PVMA and SAT were therefore not used in subsequent multivariable models. Multivariable Cox proportional hazard

Table 1 Baseline characteristics of at-risk smokers by quartile of PMA ( $N=3705)$

\begin{tabular}{|c|c|c|c|c|c|c|c|c|}
\hline \multirow{3}{*}{$\frac{\text { Variable }}{\text { Age, -yrs }}$} & \multicolumn{8}{|c|}{ PMA Quartile } \\
\hline & \multicolumn{2}{|c|}{$1\left(<31.8 \mathrm{~cm}^{2}\right)$} & \multicolumn{2}{|c|}{$2\left(31.8-41.2 \mathrm{~cm}^{2}\right)$} & \multicolumn{2}{|c|}{$3\left(41.3-53.5 \mathrm{~cm}^{2}\right)$} & \multicolumn{2}{|c|}{$4\left(>53.5 \mathrm{~cm}^{2}\right)$} \\
\hline & 61 & \pm 9 & 58 & \pm 8 & 57 & \pm 8 & 54 & \pm 7 \\
\hline Male Sex, -\% & 6 & & 33 & & 70 & & 90 & \\
\hline Non-Hispanic White, -\% & 87 & & 74 & & 66 & & 42 & \\
\hline Height, $-\mathrm{cm}$ & 163 & \pm 7 & 168 & \pm 9 & 173 & \pm 9 & 176 & \pm 8 \\
\hline BMl, $-\mathrm{kg} / \mathrm{m} 2$ & 27 & \pm 5 & 29 & \pm 6 & 30 & \pm 6 & 31 & \pm 6 \\
\hline Pack Years of Smoking & 37 & \pm 20 & 39 & \pm 22 & 40 & \pm 21 & 38 & \pm 20 \\
\hline Current Smoking Status, -\% & 42 & & 54 & & 59 & & 65 & \\
\hline Modified Medical Research Council Dyspnea Score > 1, -\% & 21 & & 29 & & 27 & & 27 & \\
\hline \multicolumn{9}{|l|}{ No. of Comorbidities ${ }^{\mathrm{a}},-\%$} \\
\hline 0 & 39 & & 37 & & 40 & & 45 & \\
\hline $1-2$ & 51 & & 51 & & 48 & & 45 & \\
\hline 3 or more & 10 & & 12 & & 12 & & 10 & \\
\hline $\mathrm{FEV}_{1},-\%$ predicted & 93 & \pm 15 & 91 & \pm 15 & 92 & \pm 16 & 92 & \pm 16 \\
\hline FVC, $-\%$ predicted & 93 & \pm 14 & 91 & \pm 14 & 91 & \pm 15 & 91 & \pm 16 \\
\hline Six-minute walk distance, $-m$ & 455 & \pm 100 & 443 & \pm 111 & 452 & \pm 114 & 456 & \pm 109 \\
\hline PMA, $-\mathrm{cm}^{2}$ & 26.2 & \pm 3.9 & 36.4 & \pm 2.7 & 46.9 & \pm 3.6 & 67.6 & \pm 14.1 \\
\hline PVMA, $-\mathrm{cm}^{2}$ & 39.8 & \pm 7.4 & 47.7 & \pm 9.9 & 56.1 & \pm 10.7 & 64.5 & \pm 12.2 \\
\hline SAT, $-\mathrm{Cm}^{2}$ & 67.9 & \pm 32.7 & 69.4 & \pm 37.2 & 58.7 & \pm 38.0 & 51.7 & \pm 37.7 \\
\hline \%LAA-950 on CT scans, -\% & 2.1 & \pm 2.8 & 2.0 & \pm 2.9 & 1.9 & \pm 2.2 & 1.2 & \pm 1.6 \\
\hline CAC score & 82 & \pm 210 & 128 & \pm 339 & 140 & \pm 309 & 105 & \pm 289 \\
\hline
\end{tabular}

Data are presented as number, proportion (percentage), and mean \pm SD

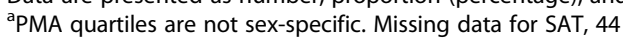




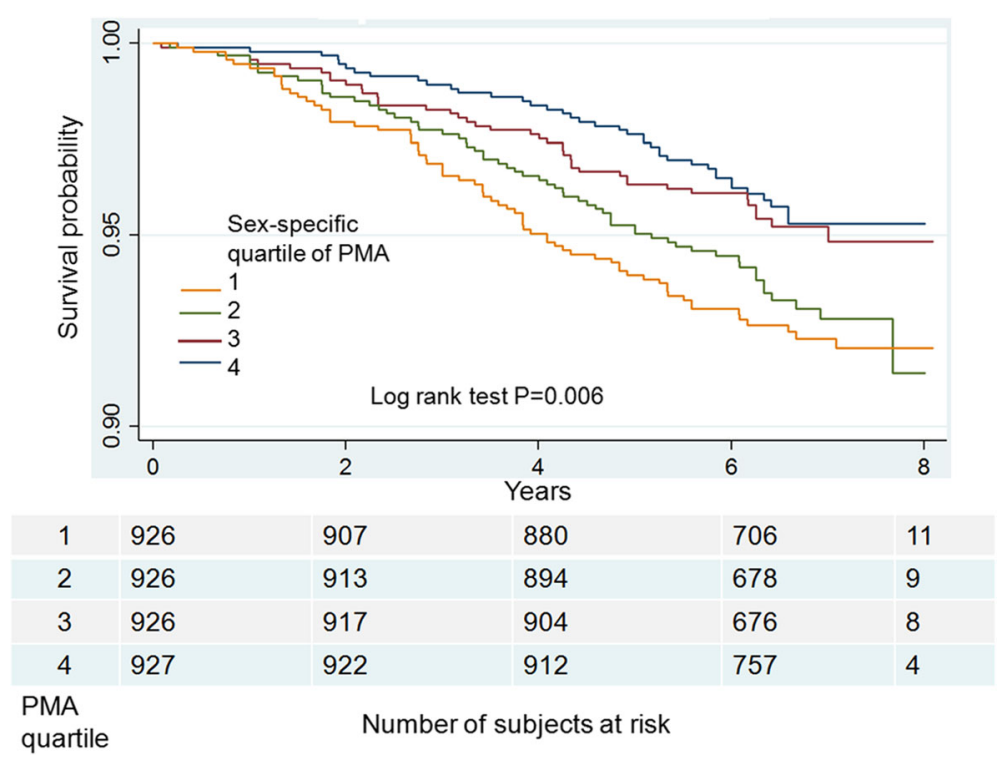

Fig. 2 Kaplan-Meier curves for all-cause mortality by sex-specific quartiles of pectoralis muscle area (PMA) in at-risk smokers. The survival probabilities decrease with decreasing PMA quartiles

model results using the measures of PMA are shown in Table 2. At-risk smokers in the lowest quartile (quartile 1) and quartile 2 had 85\% (Hazard Ratio [HR] 1.85 95\% CI [1.14-3.00] and 63\% (HR 1.63 [1.04-2.54]) higher risk of death than those in quartile 4 , respectively. The results were consistent when the index PMA/height ${ }^{2}$ (i. e., PMA as continuous variable and same covariates as for models using PMA quartiles but height and BMI) was used instead PMA quartiles (HR 0.93 [0.90-0.97] $P$ $=0.0002)$. The association between PMA and mortality was modified by smoking status $(P=0.04$ for the interaction between PMA and smoking status). Current smokers had a significantly increased risk of death (HR 2.25 [1.25-4.03] $P=0.007$ ) while former smokers did not (Table 3 ). The association between PMA and mortality was not modified by age $(P=0.57$ for the PMA-age interaction), sex $(P=0.44$ for the PMA-sex interaction), or race $(P=0.50$ for the PMA-race interaction).

Table 2 Multivariable Cox Regression models for all-cause mortality in all at-risk smokers ${ }^{a, b}$

\begin{tabular}{|c|c|c|c|c|}
\hline & $\mathrm{HR}$ & \multicolumn{2}{|l|}{$95 \% \mathrm{Cl}$} & $P$ \\
\hline \multicolumn{5}{|c|}{ Sex-specific PMA quartile } \\
\hline 4 & Ref & & & \\
\hline 3 & 1.09 & 0.70 & 1.72 & 0.70 \\
\hline 2 & 1.63 & 1.04 & 2.54 & 0.03 \\
\hline 1 & 1.85 & 1.14 & 3.00 & 0.01 \\
\hline
\end{tabular}

${ }^{a}$ Adjustment for age (years), race (non-Hispanic White, African-American), height (cm), BMI (categories $<20 ; 20-24.9 ; 25-30 ;>30$ ), pack-years of smoking (per 10), current smoking status (yes/no), mMRC dyspnea score $>1$ (yes/no), number of comorbidities (categories, $0 ; 1-2 ; \geq 3$ ), six-minute walk distance (per $30 \mathrm{~m}), \mathrm{FEV}_{1}(\mathrm{~L})$, log CAC, log \% LAA-950, and scanner type was performed

${ }^{\mathrm{b}}$ Model Proportionality Hazard Test, $\mathrm{P}=0.13$

\section{Discussion}

Low muscle mass is associated with mortality in smokers at risk for developing expiratory airflow obstruction. This association is muscle specific, modified by smoking status, and remains after adjustment for demographics, smoking history, dyspnea, comorbidities, lung function, exercise capacity, emphysema, and coronary artery calcium content.

Prior studies $[9-12,18]$ and a meta-analysis [43] have examined the association between low muscle mass or sarcopenia and mortality in different populations including community-dwelling subjects, institutionalized individuals, and patients with COPD and cancer. However, we are not aware of studies specifically exploring such an association in smokers without airflow obstruction. Our data indicate that muscle mass but not fat provides

Table 3 Multivariable Cox Regression models for all-cause mortality in at-risk smokers by smoking status ${ }^{a}$,

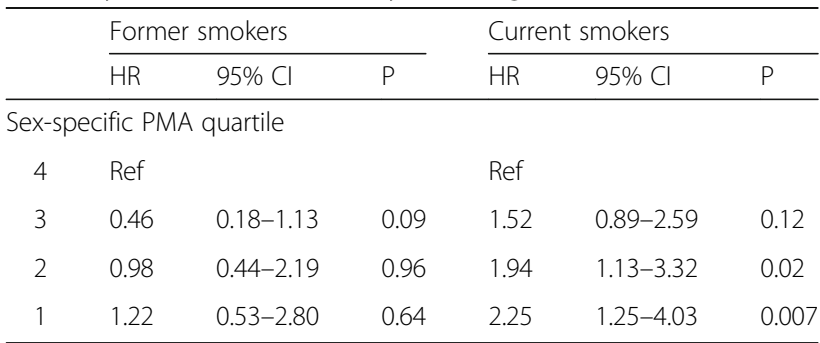

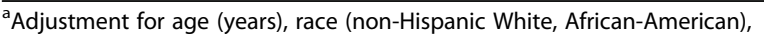
height (cm), BMI (categories $<20 ; 20-24.9 ; 25-30 ;>30$ ), pack-years of smoking (per 10), mMRC dyspnea score $>1$ (yes/no), number of comorbidities (categories, $0 ; 1-2 ; \geq 3$ ), six-minute walk distance (per 30 m), FEV ${ }_{1}(\mathrm{~L}), \log$ CAC, log \%LAA-950, and scanner type was performed

${ }^{b}$ Model Proportionality Hazard Test, $P=0.28$ and $P=0.13$ for current and former smokers, respectively 
prognostic information from body composition in this population. CT scanning can disambiguate the effects of these two components of body composition supporting its utility to further characterize body structure. Multiple studies have now documented the clinical and prognostic consequences of respiratory symptoms and emphysema measured on CT scan in smokers who do not meet the established criteria for COPD [2, 3, 44]. At-risk smokers are also the subject of ongoing therapeutic investigation focused on the improvement of healthrelated quality of life (NCT02867761 at ClinicalTrials. gov). The aggregate of our work and prior studies further supports the contention that spirometry is insufficient for determining susceptibility to injury to chronic tobacco smoke exposure because it underestimates the presence of pulmonary and extra-pulmonary disease. It is increasingly clear that multimodality assessments of smokers including techniques such as CT imaging are required to more fully determine the clinical manifestations of chronic tobacco smoke exposure.

A second compelling finding in our data was that the association between PMA and death was modified by smoking status. Thus, while among current smokers the association between low muscle mass and all-cause mortality was significant, among former smokers it was not. We believe that the mechanisms that lead to low muscle mass and increased risk of death such as systemic inflammation might be sustained in current compared to former smokers. This difference in the prognostic value of PMA-mortality may also be influenced by differential statistical power as only $1 / 3$ of the deaths occurred among former-smokers. Regardless of the reasons for the difference in risk of death between these groups of smokers, these findings further support smoking cessation as a relevant clinical intervention.

Another interesting observation was the differential associations between the PMA vs. PVMA and an increased risk of death. The PMA but not the PVMA predicted death in the at-risk cohort. The reasons for this are unclear. However, it is possible that PMA is affected by or resilient to different mechanisms of low muscle mass than that of PVMA. Those with preserved PVMA and decreased PMA may be suffering from inactivity, while those with reduced PVMA and PMA are afflicted by a consumptive inflammatory process. This conjecture requires more detailed patients' characterization, which is not available in COPDGene. An alternate explanation may be found in the distribution of the muscle areas (see Table 1). There may just be a greater biologically plausible range of PMA than PVMA. The relative superiority of PMA for predicting death may not then be directly ascribed to differential muscle wasting but that it is just easier to detect these muscles on CT scan. Perhaps another method to ascertain in-vivo muscle health with higher resolution than $\mathrm{CT}$ scan would corroborate this hypothesis. While we have provided compelling observational data linking low muscle mass and mortality in atrisk smokers, we lack the data to provide insight into the mechanisms of low muscle mass in this population. In addition to inflammation and atrophy, studies have also shown aging as a potential explanation for low muscle mass $[45,46]$. The current findings are clinically important and pave the way for future mechanistic studies to uncover novel mechanisms of low muscle mass in smokers.

There are limitations to our data that must be acknowledged. COPDGene is a study of heavy smokers and caution must be exercised when extrapolating our results to non-heavy smokers. Further research is needed to confirm our observations in other populations of smokers. Although we lack vital status information in $13 \%$ of the subjects, we still had a large cohort with complete data and over 200 events of interest allowing us including a myriad of relevant confounders in our survival models. Additionally, data on mortality cause was not available for this analysis but it is an ongoing effort in the COPDGene Study. Another inherent limitation to observational data is that conclusions cannot be drawn about the response to intervention. While it would seem to be obvious that reversing the low muscle mass in smokers would be beneficial, it is unclear if any intervention from exercise to pharmacologic therapy would improve survival even if the muscle bulk were increased.

\section{Conclusions}

In summary, a single-axial image of the pectoralis muscles seems to be prognostic for patient death in at-risk smokers. Our data provides additional evidence that the extra-pulmonary features evident on CT scan are useful for clinical investigations involving such cohorts of subjects. The PMA measurements are easy to perform and can be obtained from a broad range of CT images such as those being obtained for lung cancer screening or routine clinical care.

\section{Additional file}

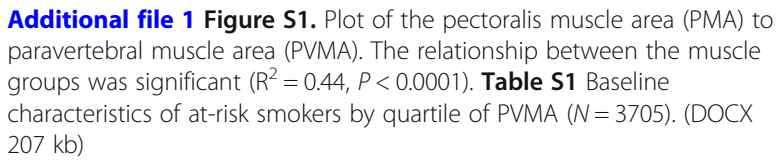

Additional file 1 Figure S1. Plot of the pectoralis muscle area (PMA) to paravertebral muscle area (PVMA). The relationship between the muscle groups was significant $\left(R^{2}=0.44, P<0.0001\right)$. Table S1 Baseline characteristics of at-risk smokers by quartile of PVMA ( $N=3705)$. (DOCX $207 \mathrm{~kb}$ )

\section{Abbreviations}

\%LAA-950: Percent of Low-attenuation Areas Less Than -950 Hounsfield Units; 6MWD: Six-minute Walk Distance; BMI: Body Mass Index;

CAC: Coronary Artery Calcium; CCC: Concordance Correlation Coefficient; COPD: Chronic Obstructive Pulmonary Disease; CT: Computed Tomography; $\mathrm{FEV}_{1}$ : Forced Expiratory Volume in 1 Second; FEV 1 /FVC: Ratio of Forced 
Expiratory Volume in 1 second to Forced Vital Capacity; FVC: Forced Vital Capacity; HU: Hounsfield Unit; PMA: Pectoralis Muscle Area;

PVMA: Paravertebral Erector Spinae Muscle Area; SAT: Subcutaneous Adipose Tissue; SD: Standard Deviation

\section{Acknowledgements}

We deeply thank to Carla Wilson for her assistance with database management and SAS programming.

\section{Funding}

This work was supported by National Institutes of Health (NIH) Grants: COPDGene, R01HL089897, R01HL089856; Dr. Diaz, K01HL118714 and the Brigham and Women's Hospital Minority Faculty Career Development Award; Dr. San José Estépar, R01 HL116473; Dr. Washko, R01 HL116473, R01 HL107246.

\section{Availability of data and materials}

The data that support the findings of this study are available from the COPDGene Study but restrictions apply to the availability of these data. Data are however available from the authors upon reasonable request and with permission of the COPDGene Study.

\section{Authors' contributions}

Conception and design of this study and creation, revision, and final approval of this manuscript: AD, CM, TY, RH, MM, JR, MH, RB, BM, ER, ES, JC, $A B, G K, J H, R S J, G W$; Analysis and interpretation: AD, GW; Data acquisition: $A D, T Y, R H, J R, R S J, G W$; Drafting the manuscript for important intellectual content: $A D, M M, M H, E R, E S, A B, G W$. Dr. Diaz and Dr. Washko take full responsibility for the content of the manuscript, including the data and analysis. The sponsor had no role in any aspect of this manuscript. All authors read and approved the final manuscript

\section{Ethics approval and consent to participate}

This study was approved by institutional review board of each of the 21 participating and all participants gave written informed consent. The Partners HealthCare Research Committee approved the current analysis (2007P000554).

\section{Consent for publication}

Not applicable.

\section{Competing interests}

Drs. AD, CM, RH, MM, JR, MH, RB, BM, ER, ES, JC, AB, GK, JH, RSJ, and GW and Mr. TY have no conflict of interest related to this work. Dr. AD has received speaker fees from Novartis Inc. unrelated to this work.

\section{Publisher's Note}

Springer Nature remains neutral with regard to jurisdictional claims in published maps and institutional affiliations.

\section{Author details}

'Division of Pulmonary and Critical Care Medicine, Department of Medicine, Brigham and Women's Hospital, Harvard Medical School, 75 Francis Street, Boston, MA 02115, USA. ²Division of Pulmonary \& Critical Care Medicine, University of Michigan Health System, Ann Arbor, MI, USA. ${ }^{3}$ Department of Radiology, Brigham and Women's Hospital, Harvard Medical School, Boston, MA, USA. ${ }^{4}$ Division of Pulmonary, Allergy and Critical Care Medicine, University of Alabama at Birmingham, Birmingham, AL, USA. ${ }^{5}$ Department of Medicine, Division of Pulmonary and Critical Care Medicine, National Jewish Health, Denver, CO, USA. ${ }^{6}$ Channing Division of Network Medicine, Brigham and Women's Hospital, Harvard Medical School, Boston, MA, USA. 'Division of Pulmonary and Critical Care Medicine, Baylor College of Medicine, Houston, Texas, USA. ${ }^{8}$ Colorado School of Public Health, University of Colorado-Denver, Aurora, CO, USA.
Received: 7 November 2017 Accepted: 4 April 2018

Published online: 10 April 2018

\section{References}

1. Jamal A, Homa DM, O'Connor E, Babb SD, Caraballo RS, Singh T, Hu SS, King BA. Current cigarette smoking among adults - United States, 2005-2014. MMWR Morb Mortal Wkly Rep. 2015;64(44):1233-40.

2. Woodruff PG, Barr RG, Bleecker E, Christenson SA, Couper D, Curtis JL, Gouskova NA, Hansel NN, Hoffman EA, Kanner RE, et al. Clinical significance of symptoms in smokers with preserved pulmonary function. N Engl J Med. 2016:374(19):1811-21.

3. Regan EA, Lynch DA, Curran-Everett D, Curtis JL, Austin JH, Grenier PA, Kauczor HU, Bailey WC, DeMeo DL, Casaburi RH, et al. Clinical and radiologic disease in smokers with normal spirometry. JAMA Intern Med. 2015;175(9): 1539-49.

4. Rom O, Kaisari S, Aizenbud D, Reznick AZ. Sarcopenia and smoking: a possible cellular model of cigarette smoke effects on muscle protein breakdown. Ann N Y Acad Sci. 2012;1259:47-53.

5. Diaz AA, Morales A, Diaz JC, Ramos C, Klaassen J, Saldias F, Aravena C, Diaz R, Lisboa C, Washko GR, et al. CT and physiologic determinants of dyspnea and exercise capacity during the six-minute walk test in mild COPD. Respir Med. 2013:107(4):570-9.

6. Kok MO, Hoekstra T, Twisk JW. The longitudinal relation between smoking and muscle strength in healthy adults. Eur Addict Res. 2012;18(2):70-5.

7. bvan den Borst B, Koster A, Yu B, Gosker HR, Meibohm B, Bauer DC, Kritchevsky SB, Liu Y, Newman AB, Harris TB, et al. Is age-related decline in lean mass and physical function accelerated by obstructive lung disease or smoking? Thorax. 2011;66(11):961-9.

8. Montes de Oca M, Loeb E, Torres SH, De Sanctis J, Hernandez N, Talamo C. Peripheral muscle alterations in non-COPD smokers. Chest. 2008;133(1):13-8.

9. Kim JH, Lim S, Choi SH, Kim KM, Yoon JW, Kim KW, Lim JY, Park KS, Jang HC Sarcopenia: an independent predictor of mortality in community-dwelling older Korean men. J Gerontol A Biol Sci Med Sci. 2014;69(10):1244-52.

10. Brown JC, Harhay MO, Harhay MN. Sarcopenia and mortality among a population-based sample of community-dwelling older adults. J Cachexia Sarcopenia Muscle. 2016;7(3):290-8.

11. Landi F, Liperoti R, Fusco D, Mastropaolo S, Quattrociocchi D, Proia A, Tosato M, Bernabei R, Onder G. Sarcopenia and mortality among older nursing home residents. J Am Med Dir Assoc. 2012;13(2):121-6.

12. Batsis JA, Mackenzie TA, Barre LK, Lopez-Jimenez F, Bartels SJ. Sarcopenia, sarcopenic obesity and mortality in older adults: results from the National Health and nutrition examination survey III. Eur J Clin Nutr. 2014;68(9):1001-7.

13. Vestbo J, Prescott E, Almdal T, Dahl M, Nordestgaard BG, Andersen T, Sorensen TI, Lange P. Body mass, fat-free body mass, and prognosis in patients with chronic obstructive pulmonary disease from a random population sample: findings from the Copenhagen City heart study. Am J Respir Crit Care Med. 2006;173(1):79-83.

14. Maltais F, Decramer M, Casaburi R, Barreiro E, Burelle Y, Debigare R, Dekhuijzen PN, Franssen F, Gayan-Ramirez G, Gea J, et al. An official American Thoracic Society/European Respiratory Society statement: update on limb muscle dysfunction in chronic obstructive pulmonary disease. Am J Respir Crit Care Med. 2014;189(9):e15-62.

15. Soler-Cataluna JJ, Sanchez-Sanchez L, Martinez-Garcia MA, Sanchez PR, Salcedo E, Navarro M. Mid-arm muscle area is a better predictor of mortality than body mass index in COPD. Chest. 2005;128(4):2108-15.

16. Gea J, Pascual S, Casadevall C, Orozco-Levi M, Barreiro E. Muscle dysfunction in chronic obstructive pulmonary disease: update on causes and biological findings. J Thorac Dis. 2015;7(10):E418-38.

17. Schols AM, Broekhuizen R, Weling-Scheepers CA, Wouters EF. Body composition and mortality in chronic obstructive pulmonary disease. Am J Clin Nutr. 2005:82(1):53-9.

18. Psutka SP, Carrasco A, Schmit GD, Moynagh MR, Boorjian SA, Frank I, Stewart SB, Thapa P, Tarrell RF, Cheville JC, et al. Sarcopenia in patients with bladder cancer undergoing radical cystectomy: impact on cancer-specific and all-cause mortality. Cancer. 2014;120(18):2910-8.

19. Hronek M, Kovarik M, Aimova P, Koblizek V, Pavlikova L, Salajka F, Zadak Z. Skinfold anthropometry-the accurate method for fat free mass measurement in COPD. Copd. 2013;10(5):597-603.

20. Nyberg A, Saey D, Maltais F. Why and how limb muscle mass and function should be measured in patients with chronic obstructive pulmonary disease. Ann Am Thorac Soc. 2015;12(9):1269-77. 
21. Jones SE, Maddocks M, Kon SS, Canavan JL, Nolan CM, Clark AL, Polkey MI Man WD. Sarcopenia in COPD: prevalence, clinical correlates and response to pulmonary rehabilitation. Thorax. 2015;70(3):213-8.

22. McDonald ML, Diaz AA, Ross JC, San Jose Estepar R, Zhou L, Regan EA, Eckbo E, Muralidhar N, Come CE, Cho MH, et al. Quantitative computed tomography measures of pectoralis muscle area and disease severity in chronic obstructive pulmonary disease. A cross-sectional study. Ann Am Thor Soc. 2014;11(3):326-34.

23. Tanimura K, Sato S, Fuseya Y, Hasegawa K, Uemasu K, Sato A, Oguma T, Hirai T, Mishima M, Muro S. Quantitative assessment of erector spinae muscles in patients with chronic obstructive pulmonary disease. Novel chest computed tomography-derived index for prognosis. Ann Am Thor Soc. 2016:13(3):334-41.

24. Marquis K, Debigare R, Lacasse $Y$, LeBlanc $P$, Jobin J, Carrier G, Maltais F. Midthigh muscle cross-sectional area is a better predictor of mortality than body mass index in patients with chronic obstructive pulmonary disease. Am J Respir Crit Care Med. 2002;166(6):809-13.

25. Martinez CH, Diaz AA, Meldrum CA, McDonald MN, Murray S, Kinney GL, Hokanson JE, Curtis JL, Bowler RP, Han MK, et al. Handgrip strength in chronic obstructive pulmonary disease. Associations with acute exacerbations and body composition. Ann Am Thor Soc. 2017;14(11):1638-45.

26. McDonald MN, Diaz AA, Rutten E, Lutz SM, Harmouche R, San Jose Estepar R, Kinney G, Hokanson JE, Gower BA, Wouters EFM et al: Chest computed tomography-derived low fat-free mass index and mortality in COPD. Eur Respir J. 2017:50(6).

27. Diaz AA, Zhou L, Young TP, McDonald ML, Harmouche R, Ross JC, San Jose Estepar R, Wouters EF, Coxson HO, MacNee W, et al. Chest CT measures of muscle and adipose tissue in COPD: gender-based differences in content and in relationships with blood biomarkers. Acad Radiol. 2014;21(10):125561.

28. Regan EA, Hokanson JE, Murphy JR, Make B, Lynch DA, Beaty TH, CurranEverett D, Silverman EK, Crapo JD. Genetic epidemiology of COPD (COPDGene) study design. Copd. 2010;7(1):32-43.

29. Diaz AA, Come CE, Ross JC, San Jose Estepar R, Han MK, Loring SH, Silverman EK, Washko GR. Association between airway caliber changes with lung inflation and emphysema assessed by volumetric $C T$ scan in subjects with COPD. Chest. 2012;141(3):736-44.

30. Gevenois PA, De Vuyst P, de Maertelaer V, Zanen J, Jacobovitz D, Cosio MG, Yernault JC. Comparison of computed density and microscopic morphometry in pulmonary emphysema. Am J Respir Crit Care Med. 1996; 154(1):187-92

31. Budoff MJ, Nasir K, Kinney GL, Hokanson JE, Barr RG, Steiner R, Nath H, Lopez-Garcia C, Black-Shinn J, Casaburi R. Coronary artery and thoracic calcium on noncontrast thoracic CT scans: comparison of ungated and gated examinations in patients from the COPD gene cohort. J CardiovasC Comput Tomogr. 2011;5(2):113-8.

32. Budoff MJ, Gul KM. Expert review on coronary calcium. Vasc Health Risk Manag. 2008;4(2):315-24.

33. McClelland RL, Chung H, Detrano R, Post W, Kronmal RA. Distribution of coronary artery calcium by race, gender, and age: results from the multiethnic study of atherosclerosis (MESA). Circulation. 2006;113(1):30-7.

34. Williams MC, Murchison JT, Edwards LD, Agusti A, Bakke P, Calverley PM, Celli B, Coxson HO, Crim C, Lomas DA, et al. Coronary artery calcification is increased in patients with COPD and associated with increased morbidity and mortality. Thorax. 2014;69(8):718-23.

35. Agatston AS, Janowitz WR, Hildner FJ, Zusmer NR, Viamonte M Jr, Detrano R. Quantification of coronary artery calcium using ultrafast computed tomography. J Am Coll Cardiol. 1990;15(4):827-32.

36. Diaz AA, Hardin ME, Come CE, San Jose Estepar R, Ross JC, Kurugol S, Okajima Y, Han MK, Kim V, Ramsdell J, et al. Childhood-onset asthma in smokers. Association between CT measures of airway size, lung function, and chronic airflow obstruction. Ann Am Thor Soc. 2014;11(9):1371-8.

37. Putcha N, Puhan MA, Hansel NN, Drummond MB, Boyd CM. Impact of comorbidities on self-rated health in self-reported COPD: an analysis of NHANES 2001-2008. Copd. 2013;10(3):324-32.

38. Romero-Corral A, Montori VM, Somers VK, Korinek J, Thomas RJ, Allison TG, Mookadam F, Lopez-Jimenez F. Association of bodyweight with total mortality and with cardiovascular events in coronary artery disease: a systematic review of cohort studies. Lancet. 2006;368(9536):666-78.

39. ATS statement: guidelines for the six-minute walk test. Am J Respir Crit Care Med. 2002;166(1):111-117.
40. Standardization of Spirometry, 1994 Update. American Thoracic Society. Am J Respir Crit Care Med 1995, 152(3):1107-1136.

41. Hankinson JL, Odencrantz JR, Fedan KB. Spirometric reference values from a sample of the general U.S. population. Am J Respir Crit Care Med. 1999: 159(1):179-87.

42. Rabe KF, Hurd S, Anzueto A, Barnes PJ, Buist SA, Calverley P, Fukuchi Y, Jenkins C, Rodriguez-Roisin R, van Weel C, et al. Global strategy for the diagnosis, management, and prevention of chronic obstructive pulmonary disease: GOLD executive summary. Am J Respir Crit Care Med. 2007;176(6): 532-55.

43. Chang SF, Lin PL. Systematic literature review and meta-analysis of the Association of Sarcopenia with Mortality. Worldviews Evid-Based Nurs. 2016; 13(2):153-62.

44. Oelsner EC, Hoffman EA, Folsom AR, Carr JJ, Enright PL, Kawut SM, Kronmal R, Lederer D, Lima JA, Lovasi GS, et al. Association between emphysema-like lung on cardiac computed tomography and mortality in persons without airflow obstruction: a cohort study. Ann Intern Med. 2014;161(12):863-73.

45. Russ DW, Gregg-Cornell K, Conaway MJ, Clark BC. Evolving concepts on the age-related changes in "muscle quality". J Cachexia Sarcopenia Muscle. 2012;3(2):95-109.

46. Delmonico MJ, Harris TB, Visser M, Park SW, Conroy MB, Velasquez-Mieyer P, Boudreau R, Manini TM, Nevitt M, Newman AB, et al. Longitudinal study of muscle strength, quality, and adipose tissue infiltration. Am J Clin Nutr. 2009;90(6):1579-85.

\section{Ready to submit your research? Choose BMC and benefit from:}

- fast, convenient online submission

- thorough peer review by experienced researchers in your field

- rapid publication on acceptance

- support for research data, including large and complex data types

- gold Open Access which fosters wider collaboration and increased citations

- maximum visibility for your research: over $100 \mathrm{M}$ website views per year

At BMC, research is always in progress.

Learn more biomedcentral.com/submissions 